\title{
Effect of Sex on Neutrophil to Lymphocyte Ratio and Coronary Flow in ST-Elevation Myocardial Infarction Patients Undergoing Primary Percutaneous Coronary Intervention
}

\author{
Amr Elkammash ${ }^{\mathrm{a}, \mathrm{c}}\left(\mathbb{D}\right.$, Mohamed Sobhy $^{\mathrm{b}}$, Amr Zaki $^{\mathrm{b}}$, Sherif Ayad ${ }^{\mathrm{b}}$, Saleh Kanaan ${ }^{\mathrm{a}}$, \\ Mohammed Fadul ${ }^{\mathrm{a}}$, Khaled Madi ${ }^{\mathrm{a}}$
}

\begin{abstract}
Background: Female patients show poorer outcomes after coronary interventions compared to males. This study aims to investigate the role of enhanced inflammatory response in female ST-elevation myocardial infarction (STEMI) patients in poor outcomes post primary percutaneous coronary intervention (PPCI).

Methods: This study included 120 STEMI patients who went to PPCI in two tertiary cardiac centers over 6 months. All STEMI patients who are eligible for PPCI are included. We excluded those who had previous coronary artery bypass grafting $(\mathrm{CABG})$ with venous grafts, previous PCI with in-stent restenosis (ISR), and those who had signs of infection on admission. These are then divided into two groups according to sex (males and females). Impaired coronary flow (also known as no-reflow) is defined as a coronary TIMI (thrombolysis in myocardial infarction) flow less than 3 after PCI in the absence of mechanical coronary occlusion.
\end{abstract}

Results: The studied groups included 88 males and 32 females. The median age in females was higher than males (62 vs. 57.5 years respectively, $\mathrm{P}=0.005$ ). The prevalence of hypertension ( $34 \mathrm{vs.} 21$ patients, $\mathrm{P}=0.01$ ), non-insulin-dependent diabetes mellitus (NIDDM) ( 22 vs. 16 patients, $\mathrm{P}=0.01)$ and smoking (61 vs. 0 patients, $\mathrm{P}<$ 0.001 ) was higher in male patients. The incidence of impaired coronary flow did not differ significantly between the two groups (10 males and six females, $\mathrm{P}=0.363$ ). The median neutrophil to lympho-

Manuscript submitted December 13, 2021, accepted January 14, 2022

Published online January 29, 2022

aDepartment of General Internal Medicine, University Hospitals Dorset NHS Foundation Trust, The Royal Bournemouth Hospital, Bournemouth, UK

${ }^{\mathrm{b} C a r d i o l o g y}$ Department, Alexandria Main University Hospitals, Alexandria, Egypt

${ }^{\mathrm{c} C}$ Corresponding Author: Amr Elkammash, Department of General Interna Medicine, University Hospitals Dorset NHS Foundation Trust, The Royal Bournemouth Hospital, Bournemouth BH7 7DW, UK.

Email: amr.elkammash@nhs.net

doi: https://doi.org/10.14740/cr1345 cyte $(\mathrm{N} / \mathrm{L})$ ratio showed to be non-significantly higher in females $(5$ in males vs. 6 in females, $\mathrm{P}=0.342$ ). However, the mean $\mathrm{N} / \mathrm{L}$ ratio was significantly higher in female patients with impaired coronary flow compared to males ( 9.35 vs. $5.79, \mathrm{P}=0.003)$.

Conclusions: The enhanced inflammatory response in female STEMI patients may be responsible for poorer outcomes after PPCI. Largerscale studies are required to define immune mechanisms as a potential target to improve outcomes in STEMI patients.

Keywords: Neutrophils; Lymphocytes; Coronary; Primary; Flow; TIMI; Ratio; Sex

\section{Introduction}

There are several pieces of evidence about the female sex as an independent predictor of poorer cardiovascular outcomes in ischemic heart disease (IHD) patients who had percutaneous coronary intervention (PCI) [1]. This also applies to female ST-elevation myocardial infarction (STEMI) patients who had primary percutaneous coronary intervention (PPCI) [2]. The mechanism behind this finding is not entirely clear. The risk remained even after the results are adjusted for other cardiovascular risk factors $[2,3]$.

Inflammation is an important step in atherosclerosis and its progression [4]. Mediators secreted by neutrophils cause vessel wall degeneration; however, lymphocytes have anti-atherosclerosis action and control the inflammatory response [5]. The neutrophil to lymphocyte $(\mathrm{N} / \mathrm{L})$ ratio is an inflammatory marker that is associated with the development of cardiovascular risk factors (hypertension, diabetes, and chronic kidney disease) and adverse cardiovascular outcomes in patients with IHD and acute coronary syndromes [6].

Our study group has hypothesized that the poor outcomes in female STEMI patients after PPCI is partially mediated by an exaggerated inflammatory response in those patients. We used the $\mathrm{N} / \mathrm{L}$ ratio as a marker to reflect the degree and the nature of the inflammatory response. 
Table 1. Clinical Characteristics and Cardiovascular Risk Factors in the Studied Groups

\begin{tabular}{llll}
\hline Parameter & Males & Females & P value \\
\hline Number (n) & 88 & 32 & - \\
Age, median \pm SD (years) $^{\mathrm{a}}$ & $57.5 \pm 10.4$ & $62 \pm 8.12$ & 0.005 \\
History of hypertension (n, \%) $^{\mathrm{b}}$ & $34(38.6 \%)$ & $21(65.6 \%)$ & 0.001 \\
NIDDM (n, \%) & $22(25 \%)$ & $16(50 \%)$ & 0.01 \\
IDDM (n, \%) & $4(4.5 \%)$ & $7(21.8 \%)$ & 0.008 \\
Smoking $(\mathrm{n}, \%)^{\mathrm{c}}$ & $61(69.3 \%)$ & $0(0 \%)$ & $<0.001$ \\
Dyslipidemia on admission $(\mathrm{n}, \%)^{\mathrm{b}}$ & $53(60.2 \%)$ & $16(50 \%)$ & 0.32 \\
\hline
\end{tabular}

aMann-Whitney U-test. ${ }^{b}$ Chi-square test. ${ }^{C}$ Fisher's exact test. NIDDM: non-insulin-dependent diabetes mellitus; IDDM: insulin-dependent diabetes mellitus; SD: standard deviation.

\section{Materials and Methods}

\section{Subjects}

Over 6 months, we enrolled 120 consecutive STEMI patients from two PPCI centers (Alexandria Main University Hospitals and International Cardiac Center, Alexandria, Egypt). We studied the patients in a prospective cohort pattern. We divided the patients into two groups; males and females. All patients who were eligible for PPCI according to European Society of Cardiology (ESC) guidelines were included [7]. Exclusion criteria included: patients who underwent coronary artery bypass grafting with venous grafts, patients who had previous stents and coming with in-stent restenosis, and patients who had infections.

\section{Ethical issues and informed consent}

All the study procedures were explained to the patients and informed consent was obtained before enrollment. All the study procedures were conducted following the Helsinki Declaration for research on human beings. The study protocol was approved by the research ethics committee at Alexandria University, Egypt, with approval number 770829/13.

\section{Data collection}

A thorough history, a complete physical examination, and a 12lead electrocardiogram (ECG) were obtained for all patients. A full blood count was sent for all subjects. The neutrophils and lymphocytes counts were analyzed using high accuracy automated laboratory analyzers. The final coronary blood flow was checked by a blinded experienced consultant in interventional cardiology. Impaired coronary blood flow (also known as no-reflow) is defined as a final TIMI (thrombolysis in myocardial infarction) coronary flow less than 3 without a mechanical coronary occlusion.

\section{Statistics}

We described the qualitative variables as number and per- centage, and the quantitative variables as mean, median, and standard deviation. When more than $20 \%$ of the cells have an expected count of less than 5, correction for Chi-square was conducted using Fisher's exact test. The distributions of quantitative variables were tested for normality using the Kolmogorov-Smirnov test, Shapiro-Wilk test, and D'Agostino test. Histogram and QQ plot were also used for a visual test. If it reveals normal data distribution, parametric tests were applied. If the data were abnormally distributed, non-parametric tests were used. For normally distributed data, comparison between two independent populations was done using an independent $t$-test, while abnormally distributed data were assessed using the Mann-Whitney test. Significance test results are quoted as two-tailed probabilities. The significance of the obtained results was judged at the $5 \%$ level. The rank-biserial correlation ( $\mathrm{r}$ ) and the Cramer's V test were used to further assess the effect size whenever the $\mathrm{P}$ value reached the threshold of significance [8]. A professional statistician fed the data to the computer and analyzed it using IBM SPSS software package version 21.0.

\section{Results}

The male group included 88 patients and the female group included 32 patients. The characteristics of the studied groups are presented in Table 1. The median age in the male group was 57.5 years and in the female group was 62 years of age. Such difference was statically significant $(\mathrm{P}=0.005)$. Further statistical analysis showed a small effect of such difference $(r$ $=0.26$ ). To ensure that the final results are not affected by the age difference, a Pearson correlation analysis was performed to test the association between age and $\mathrm{N} / \mathrm{L}$ ratio. This did not show any association between these variables (correlation coefficient $\mathrm{r}=0.13, \mathrm{P}=0.146$ ). The hypertension was more prevalent among the male group (34 male vs. 21 female patients, $\mathrm{P}=0.01)$. The number of diabetics on oral medications was significantly higher in the male group (22 males vs. 16 females, $\mathrm{P}=0.01)$. The effect of sex in this group was checked using Cramer's V test and was found to be small (Cramer's $\mathrm{V}=0.24)$. The number of diabetics who were taking insulin was higher in the female group (seven females vs. four males, $\mathrm{P}=0.008)$. Cramer's V test also showed the 




Figure 1. The incidence of impaired coronary blood flow among the studied males and females. Green bars: good TIMI 3 flow. Red bars: impaired flow below TIMI 3. TIMI: thrombolysis in myocardial infarction.

effect of sex was small on the observed difference (Cramer's $\mathrm{V}=0.27)$. Sixty-one smokers were found among male patients; however, none of the female patients was smoking. There was not a significant difference in the prevalence of dyslipidemia among males and females (53 vs. 16 patients respectively, $\mathrm{P}=0.32$ ).

The incidence of impaired coronary flow did not differ significantly between males and females (10 vs. six patients, respectively, $\mathrm{P}=0.363$ ) (Fig. 1). The median of $\mathrm{N} / \mathrm{L}$ ratio tended to be higher in females, but such difference did not reach the threshold for statistical significance ( 5 in males vs. 6 in females, $\mathrm{P}=0.342$ ) (Fig. 2, Table 2). A sub-analysis for the N/L among patients who suffered impaired coronary flow post-PPCI showed that the mean of N/L ratio was significantly higher in female patients with the impaired coronary flow with a strong $\mathrm{P}$ value (9.35 in females vs. 5.79 in males, $\mathrm{P}=0.003$ ) (Fig. 3, Table 3).

\section{Discussion}

Our study demonstrates that female STEMI patients tend to show a higher N/L ratio compared to male patients, such phenomenon was quite obvious in those who developed impaired coronary flow after PPCI.

We have chosen the N/L ratio as a marker of inflammation as it has stronger evidence of predicting cardiovascular outcomes compared to other inflammatory markers such as C-reactive protein (CRP). Few studies have shown that CRP could not predict 30-day [9] and long-term [10] outcomes. The high N/L ratio spotted the patients with increased cardiovascular morbidity when their CRP level was low [11]. CRP reduction has not improved clinical outcomes when was set as a therapeutic target [12]. Researchers found promising results on the improvement of cardiac remodeling and post-myocardial

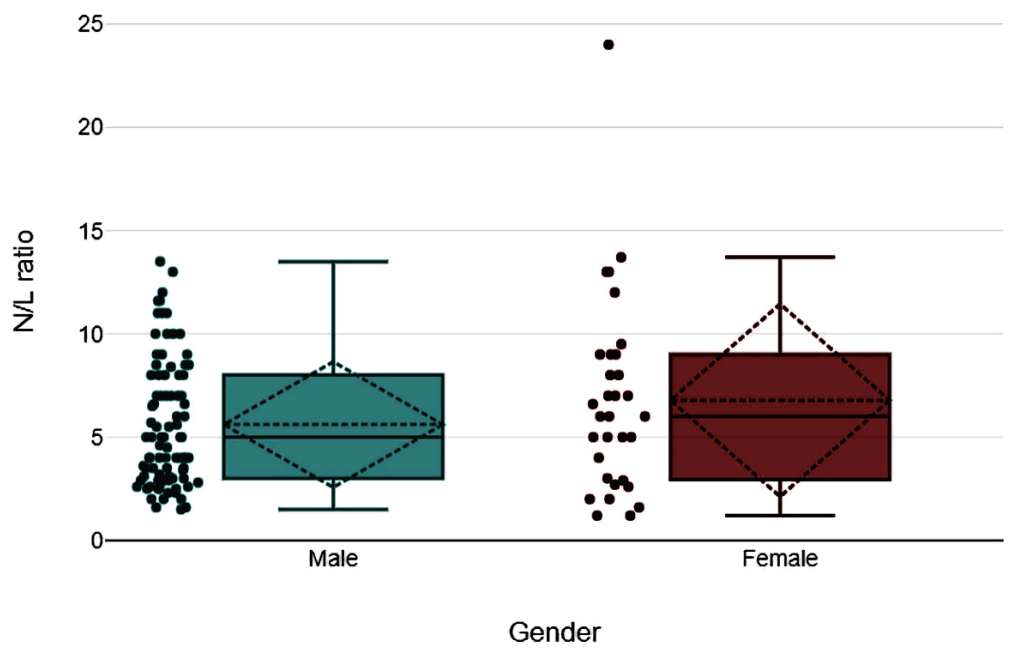

Figure 2. Box plot representing neutrophil to lymphocyte $(\mathrm{N} / \mathrm{L})$ ratio values in the studied males and females. The solid horizontal line in the box represents the median, while the dotted one represents the mean. 
Table 2. The Incidence of Impaired Coronary Flow and the N/L Ratio in the Studied Groups

\begin{tabular}{llll}
\hline Parameter & $\begin{array}{l}\text { Males } \\
(\mathbf{n = 8 8})\end{array}$ & $\begin{array}{l}\text { Females } \\
(\mathbf{n = 3 2})\end{array}$ & P value \\
\hline Impaired coronary flow $(\mathrm{n})^{\mathrm{a}}$ & 10 & 6 & 0.363 \\
N/L ratio (median $\pm \mathrm{SD})^{\mathrm{b}}$ & $5 \pm 3.05$ & $6 \pm 4.73$ & 0.342 \\
\hline
\end{tabular}

aFisher's exact test. 'Mann-Whitney U-test. N/L: neutrophil to lymphocyte; SD: standard deviation.

infarction outcomes when targeting neutrophils' receptors and neutrophil-released inflammatory mediators [13, 14].

We believe the noted increase in age in the female group is due to the characteristics of the studied population. Cardiovascular risk factors (hypertension, diabetes and smoking) were more prevalent in the male group. Sex hormones confer protection to females against atherosclerotic coronary artery disease. This also makes them present at a later age closer to menopause. When we assessed the effect size of age difference in different sex groups, it was small. There was no correlation between age and N/L ratio on running a Pearson correlation analysis. Studies showed that as females get older, they produce more lymphocytes in response to inflammation leading to a lower $\mathrm{N} / \mathrm{L}$ ratio $[15,16]$. Therefore, the perceived increase in the $\mathrm{N} / \mathrm{L}$ ratio in the female group was not due to the increase of median age in females.

Although there was a statistically significant difference between the males and females regarding the history of hypertension and type of diabetes, the effect of sex was found to be small on further analysis using Cramer's V test. This finding is not against what is already known about the higher prevalence of hypertension [17] and type 2 diabetes mellitus [18] in males.

Several studies showed that female patients with IHD have poorer outcomes after coronary interventions compared to their male counterparts $[1,19]$. The cause for such a find-
Table 3. The N/L Ratio in Patients With Impaired Coronary Flow Post PPCI

\begin{tabular}{llll}
\hline Parameter & Males & Females & P value \\
\hline Number & 10 & 6 & 0.363 \\
N/L ratio $(\text { mean } \pm \mathrm{SD})^{\mathrm{a}}$ & $5.79 \pm 1.89$ & $9.35 \pm 2.06$ & 0.003 \\
\hline
\end{tabular}

aStudent's independent samples t-test. PPCl: primary percutaneous coronary intervention; N/L: neutrophil to lymphocyte; SD: standard deviation.

ing was not clear. A meta-analysis that included 2,632 patients showed that female STEMI patients who had PPCI had higher 1 -year mortality and heart failure hospitalization compared to male patients despite the absence of a significant difference in the infarct size between both groups and high left ventricular ejection fraction in female patients [20].

Females usually have a higher peripheral neutrophil count compared to males $[21,22]$. On the other hand, males tend to show a higher peripheral lymphocytic count [23]. This leads to a higher $\mathrm{N} / \mathrm{L}$ in females. There is robust evidence in the literature that a high N/L ratio is a predictor of high morbidity and mortality in STEMI patients who underwent PPCI [24]. A clue on this fact was demonstrated in our study, where the female patients with impaired coronary flow showed a higher N/L ratio compared to the male group. This may be an answer to the difference in cardiovascular outcomes between sexes post PPCI. Such finding needs further confirmation by larger-scale randomized studies before considering immune mechanisms as a target to improve outcomes in STEMI patients.

\section{Limitations to the study}

We did the study on a relatively small number of patients,

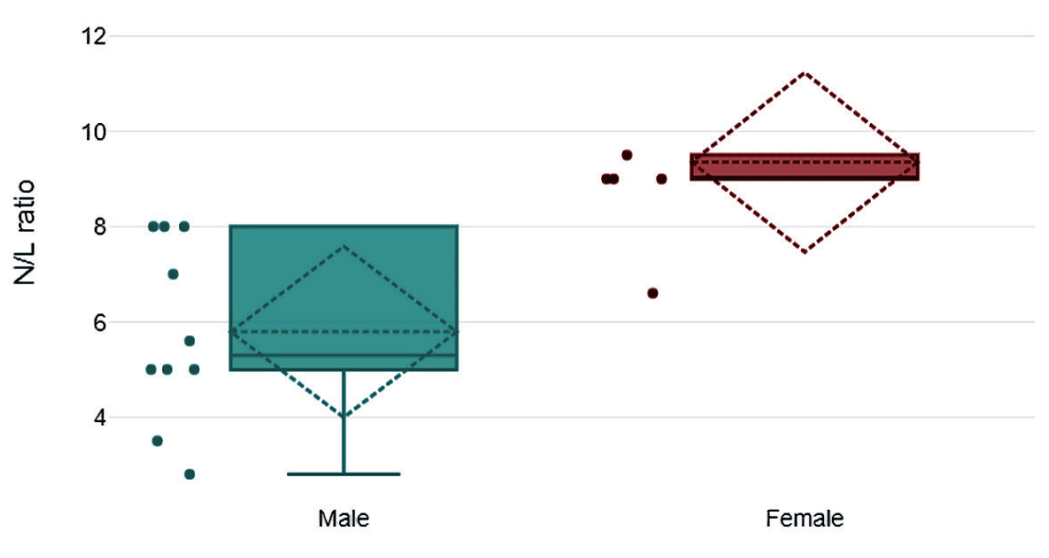

$\operatorname{sex}$

Figure 3. Box plot representing the neutrophil to lymphocyte (N/L) ratio values among the studied males and females with impaired coronary blood flow $(\mathrm{TIMI}<3)$. The solid horizontal line in the box represents the median, while the dotted one represents the mean. TIMI: thrombolysis in myocardial infarction. 
which can make it difficult to generalize the findings. However, our findings are adding to the body of evidence already present on the involvement of immune mechanisms in defining the outcome after PPCI. Another point is that the menstrual history and the ethnic group were not studied in the recruited patients. Both factors were found to affect the peripheral differential leukocytic count in females $[25,26]$. We have not assessed other inflammatory markers in this study (e.g., CRP). It would add to the value of the study if these were measured and compared to the $\mathrm{N} / \mathrm{L}$ ratio in regards to the ability to predict poor clinical outcomes in STEMI patients.

\section{Conclusions}

Sex hormones affect the immune mechanism in patients with IHD. This leads to a higher N/L ratio in female patients. Such finding can be incriminated, at least partially, in the poorer cardiovascular outcomes in female patients. Larger studies are required to confirm the role of immune mechanisms in cardiovascular outcomes and target them to improve healthcare for coronary artery disease patients.

\section{Acknowledgments}

We thank Mr. Salih Firat Canpolat (Yasar University, Turkey) for his assistance with the statistical analysis of this work.

\section{Financial Disclosure}

No specific funding source to declare.

\section{Conflict of Interest}

None to declare.

\section{Informed Consent}

Informed consents were obtained.

\section{Author Contributions}

AE, SA, MS, and AZ conceptualized the research project. AE, $\mathrm{SK}, \mathrm{MF}$ and $\mathrm{KM}$ did the literature review. AE collected the data. AE, SK, MF, and KM did the statistical analysis. AE prepared the first draft. MS, AZ, and SA critically reviewed the manuscript. AE did the manuscript revision and submission.

\section{Data Availability}

The data supporting the findings of this study are available from the corresponding author upon reasonable request.

\section{References}

1. Guo Y, Yin F, Fan C, Wang Z. Gender difference in clinical outcomes of the patients with coronary artery disease after percutaneous coronary intervention: A systematic review and meta-analysis. Medicine (Baltimore). 2018;97(30):e11644.

2. Benamer H, Tafflet M, Bataille S, Escolano S, Livarek B, Fourchard V, Caussin C, et al. Female gender is an independent predictor of in-hospital mortality after STEMI in the era of primary PCI: insights from the greater Paris area PCI Registry. EuroIntervention. 2011;6(9):10731079.

3. Pu J, Shan P, Ding S, Qiao Z, Jiang L, Song W, Du Y, et al. Gender differences in epicardial and tissue-level reperfusion in patients undergoing primary angioplasty for acute myocardial infarction. Atherosclerosis. 2011;215(1):203208.

4. Hoffman M, Blum A, Baruch R, Kaplan E, Benjamin M. Leukocytes and coronary heart disease. Atherosclerosis. 2004;172(1):1-6.

5. Venkatraghavan L, Tan TP, Mehta J, Arekapudi A, Govindarajulu A, Siu E. Neutrophil Lymphocyte Ratio as a predictor of systemic inflammation - A cross-sectional study in a pre-admission setting. F1000Res. 2015;4:123.

6. Angkananard T, Anothaisintawee T, Ingsathit A, McEvoy M, Silapat K, Attia J, Sritara P, et al. Mediation effect of neutrophil lymphocyte ratio on cardiometabolic risk factors and cardiovascular events. Sci Rep. 2019;9(1):2618.

7. Ibanez B, James S, Agewall S, Antunes MJ, BucciarelliDucci C, Bueno H, Caforio ALP, et al. 2017 ESC Guidelines for the management of acute myocardial infarction in patients presenting with ST-segment elevation: The Task Force for the management of acute myocardial infarction in patients presenting with ST-segment elevation of the European Society of Cardiology (ESC). Eur Heart J. 2018;39(2):119-177.

8. Lee DK. Alternatives to P value: confidence interval and effect size. Korean J Anesthesiol. 2016;69(6):555-562.

9. Mega JL, Morrow DA, De Lemos JA, Sabatine MS, Murphy SA, Rifai N, Gibson CM, et al. B-type natriuretic peptide at presentation and prognosis in patients with STsegment elevation myocardial infarction: an ENTIRETIMI-23 substudy. J Am Coll Cardiol. 2004;44(2):335339.

10. Nikfardjam M, Mullner M, Schreiber W, Oschatz E, Exner M, Domanovits H, Laggner AN, et al. The association between $\mathrm{C}$-reactive protein on admission and mortality in patients with acute myocardial infarction. J Intern Med. 2000;247(3):341-345.

11. Wada H, Dohi T, Miyauchi K, Nishio R, Takeuchi M, Takahashi N, Endo H, et al. Neutrophil to lymphocyte ratio and long-term cardiovascular outcomes in coronary artery disease patients with low high-sensitivity C-reactive protein level. Int Heart J. 2020;61(3):447-453.

12. Berkley A, Ferro A. Changes in C-reactive protein in response to anti-inflammatory therapy as a predictor of cardiovascular outcomes: A systematic review and meta-anal- 
ysis. JRSM Cardiovasc Dis. 2020;9:2048004020929235.

13. Carbone F, Nencioni A, Mach F, Vuilleumier N, Montecucco F. Pathophysiological role of neutrophils in acute myocardial infarction. Thromb Haemost. 2013;110(3):501514.

14. Vinten-Johansen J. Involvement of neutrophils in the pathogenesis of lethal myocardial reperfusion injury. Cardiovasc Res. 2004;61(3):481-497.

15. Wu L, Zou S, Wang C, Tan X, Yu M. Neutrophil-to-lymphocyte and platelet-to-lymphocyte ratio in Chinese Han population from Chaoshan region in South China. BMC Cardiovasc Disord. 2019;19(1):125.

16. Lee JS, Kim NY, Na SH, Youn YH, Shin CS. Reference values of neutrophil-lymphocyte ratio, lymphocytemonocyte ratio, platelet-lymphocyte ratio, and mean platelet volume in healthy adults in South Korea. Medicine (Baltimore). 2018;97(26):e11138.

17. Santosa A, Zhang Y, Weinehall L, Zhao G, Wang N, Zhao Q, Wang W, et al. Gender differences and determinants of prevalence, awareness, treatment and control of hypertension among adults in China and Sweden. BMC Public Health. 2020;20(1):1763.

18. Nordstrom A, Hadrevi J, Olsson T, Franks PW, Nordstrom P. Higher prevalence of type 2 diabetes in men than in women is associated with differences in visceral fat mass. J Clin Endocrinol Metab. 2016;101(10):3740-3746.

19. Rao U, Buchanan GL, Hoye A. Outcomes after percutaneous coronary intervention in women: are there differences when compared with men? Interv Cardiol. 2019;14(2):70-75.

20. Kosmidou I, Redfors B, Selker HP, Thiele H, Patel MR,
Udelson JE, Magnus Ohman E, et al. Infarct size, left ventricular function, and prognosis in women compared to men after primary percutaneous coronary intervention in ST-segment elevation myocardial infarction: results from an individual patient-level pooled analysis of 10 randomized trials. Eur Heart J. 2017;38(21):16561663.

21. Bain BJ, England JM. Normal haematological values: sex difference in neutrophil count. $\mathrm{Br}$ Med J. 1975;1(5953):306-309.

22. Rathod KS, Kapil V, Velmurugan S, Khambata RS, Siddique U, Khan S, Van Eijl S, et al. Accelerated resolution of inflammation underlies sex differences in inflammatory responses in humans. J Clin Invest. 2017;127(1):169182.

23. Abdullah M, Chai PS, Chong MY, Tohit ER, Ramasamy $\mathrm{R}$, Pei CP, Vidyadaran S. Gender effect on in vitro lymphocyte subset levels of healthy individuals. Cell Immunol. 2012;272(2):214-219.

24. Zhang S, Diao J, Qi C, Jin J, Li L, Gao X, Gong L, et al. Predictive value of neutrophil to lymphocyte ratio in patients with acute ST segment elevation myocardial infarction after percutaneous coronary intervention: a metaanalysis. BMC Cardiovasc Disord. 2018;18(1):75.

25. Chen Y, Zhang Y, Zhao G, Chen C, Yang P, Ye S, Tan $\mathrm{X}$. Difference in leukocyte composition between women before and after menopausal age, and distinct sexual dimorphism. PLoS One. 2016;11(9):e0162953.

26. Bain BJ. Ethnic and sex differences in the total and differential white cell count and platelet count. J Clin Pathol. 1996;49(8):664-666. 